Article

\title{
Understanding and Managing Vacant Houses in Support of a Material Stock-Type Society-The Case of Kitakyushu, Japan
}

\author{
Wendy Wuyts ${ }^{1, * \mathbb{D}}$, Raphael Sedlitzky ${ }^{2}$, Masato Morita ${ }^{1}$ and Hiroki Tanikawa ${ }^{1}$ \\ 1 Graduate School of Environmental Studies, Nagoya University, Aichi 464-8601, Japan; \\ morita.masato@j.mbox.nagoya-u.ac.jp (M.M.); tanikawa@nagoya-u.jp (H.T.) \\ 2 Institute for Geography and Regional Research, University of Vienna, 1010 Vienna, Austria; \\ raphael.sedlitzky@outlook.com \\ * Correspondence: wendywwuyts@gmail.com
}

Received: 7 May 2020; Accepted: 28 June 2020; Published: 2 July 2020

\begin{abstract}
From a sustainable material management perspective, vacant houses represent material stock and still have potential in the circular economy. This article addresses two aspects of understanding and managing vacant houses: the difficulty of understanding their spatial and temporal patterns and the management of the social costs behind the phenomenon of vacant houses. These aspects are approached by combining a 4D GIS analysis with expert interviews and additional qualitative tools to assess the spatial and temporal dimension of vacant houses. Furthermore, this manuscript presents a tool to estimate the obsolete dwelling material stock distribution within a city. The case of the city of Kitakyushu demonstrates the relationship that exists between the historical trajectories of housing norms and standards, such as comfort, cleanliness, safety, and convenience, and the dynamics of the built material stock and demography for three selected neighbourhoods. The results show that the more locked-in a district is in terms of "obsolete norms and codes", the more likely it is that the obsolete stock is dead, and consequently, urban mining should be considered. The article concludes that a revisiting of the norms and standards of convenience and other domains is one of the prerequisites of the transition toward a circular built environment and the prevention of obsolete stock accumulation.
\end{abstract}

Keywords: circular city; material stock analysis; historical trajectories; housing norms; obsolescence; urban design

\section{Introduction}

"Empty houses" do not occur in helpful clusters. Rather than an urban cancer, to be cut out by abandoning the declining neighbourhood, they are a kind of urban measles. Individual houses fall empty in every neighbourhood when their owners grow old. For Japan's mayors, measles is the more painful disease. They are left with the same costs-the same lengths of road and number of primary schools are required-but an ever-falling population of taxpayers who can pay for it all [1].

Japan is a country with a rapidly ageing population [2] and many vacant houses. According to the latest survey, the national residential vacancy rate reached a new record of 13.6\% [3]. Harding's metaphor draws attention to two crucial aspects that Japan is called to face: the difficulty of understanding the spatial-temporal development of vacant houses within urban areas, and the management of the social costs related to this phenomenon.

Although Harding claims a lack of specific spatial patterns behind the vacant houses, recent Japanese studies in geography have revealed different dynamics for different areas within cities, 
especially when they added in a temporal component [4]. According to the studies of the spatial distribution of vacant houses within city boundaries, Nishiyama (2019) identified that vacant houses in megacities like Tokyo are mostly situated in suburban areas, while smaller cities tend to experience vacancies mostly in the city centres [5]. This article verifies these findings and uses this understanding to propose and discuss solutions.

To examine the second aspect, this article assesses the societal, economic, and historical context in which the phenomenon occurs and proposes measures to prevent and reduce the social (e.g., weakened social fabric) and environmental costs (e.g., leakage to the environment, avoided material extraction) of vacant houses. There is a large number of vacant houses scattered around Japan. In addition, the average lifespan of Japanese houses is only 20-30 years [6], which leads to a high demand for construction materials. Considering the push towards urban sustainability, academic experts are advocating that societies move from the continuous construction of new buildings to a circular built environment [7]. While the first term conveys the practice of constructing and demolishing without efforts to reduce the environmental and other impacts, the latter term encompasses practices in design, construction, maintenance, and deconstruction that are in line with circular economy (CE) principles. As part of this shift, the study of vacant houses in shrinking cities will be increasingly important going forward. First, although age-related vacancy is mainly found in Japan, many rapidly growing cities are dealing with underused material stocks, and regions of Europe and the USA are already coping with the social costs $[8,9]$. In addition, temporary vacant housing should not be considered a social problem because old temporary residential areas may attract future investment [10]. However, when vacant housing is a symptom of permanent stagnation, as in the case of many Japanese cities, this social problem, when not managed in the right way, can lead to social disorder and the expansion of slum-like areas [10]. Mobilising vacant houses can also be considered as a strategy in the transition toward circular cities. In this regard, it might seem surprising that the spatial dimension of the circular economy has not been explored well in the existing research. One reason could be that in industrial ecology, which is one of the fields at the foundation of the circular economy [11], space is a rather neglected dimension and the circular economy is often seen solely as the sum of businesses [12]. This manuscript aims to address this gap in the research on the urban circular economy by including space as a resource in the model. In other words, buildings are not only stocks of materials, but also stocks of space and should therefore be included in any local sustainable development strategy. Hence, in circular cities, buildings should serve societies for as long as possible; when their service time ends, the buildings should function as a reservoir of secondary materials and urban mining (the practice of recovering secondary resources from obsolete sinks of materials in cities) [13], which could help reduce the embodied environmental impacts [14].

In Japan, the vision of a "material stock"-type society was put forth by the Japanese Ministry of the Environment in 1999: "a society in which construction, infrastructure, and products are used for a long period of time" [15]. In this type of society, the quality of material stocks is improved, and low-value stocks are replaced to serve society in the most efficient way. This implies a longer and more intense service use, which results in extracting fewer primary resources and slower material flows. Policymakers need to understand and manage the resource accumulation embedded in buildings and infrastructure to prevent a shortage of services like housing and mobility. Transforming the linear metabolism of materials into a circular one could guarantee the continued use of older materials and thereby contribute to sustainable urban development. For cities, this means that such an approach can also help to reduce urban sprawl, which is not just ecologically but also economically unsustainable [16]. While the energy, materials, money, time, and other resources embodied in these vacant houses are fixed and not serving society, their presence hinders compact city planning and stimulates urban sprawl. Therefore, this paper aims to contribute to the understanding and managing of this obsolete housing stock to support a material stock-type society.

Recent developments in the theory of the circular economy have embraced this concept. In fact, as in the concept of a material stock society, the circular economy theory advocates a model of the 
economy where the material loops are narrowed and slowed down, and quality of life is improved. This article focuses on the potential of urban mining [17] and other circular economy practices for dealing with these obsolete material stocks [18]. First, some stakeholders might perceive the obsolescence of a house differently depending on their know-how and prioritised criteria, and might have different opinions about when the (social) costs of a vacant house are too high, and hence, which circular economy strategy is best for reducing these costs. To guarantee the success of the implementation, it is essential to understand the perspectives of local stakeholders on vacant houses and the current norms and standards for a home, which influence their adjustment behaviour [19]. Potential and previous homeowners have housing needs that can be derived from "cultural standards against which actual housing conditions are judged" [19]. Few scholars researching building material stock have engaged with homeowner and consumer sciences to understand the changes in norms and standards for the built environment over time [6], so more research is required on housing adjustment theories, urban planning, and material stock in order to identify feasible circular economy options.

The majority of material stock research discusses delaying building obsolescence [6,20], increasing the average building lifetime [21], or investigating durability [7] as essential strategies for the transition toward a circular and therefore more sustainable built environment. A common finding of these scholars is the need for research that can account for and communicate, at the right moment, which materials in what quantities and where in the city become available for urban mining, and other circular economy strategies [22]. Whereas industrial actors are more interested in detailed accounts, more economy-wide insights can help policymakers develop place-specific circular economy strategies for different materials [12].

Hence, this article applies a model of a circular economy approach for obsolete housing proposed by Wuyts et al. (2019) to assess the problem of permanent vacant houses in a city [6]. The study behind this model integrated the idea of cultural norms that influence the evaluation of houses by residing families. This model resulted from observations in Onomichi, a model town in Japan coping with vacancies. Some vacant houses in this model town were demolished and replaced by green areas and playgrounds for children. Other vacant houses could be restored and repurposed. The limit of this model is that it has not been tested in other cities. Hence, the novelty of this study is that it applies this model for the first time and evaluates this.

As this article intends to understand the roots of the problem and identify opportunities for reducing or reactivating this stock of embodied materials, we propose additional tools to be integrated to map the spatial and temporal patterns of vacant houses within the boundaries of a city as a heuristic amendment to the existing model.

As a case study we analysed Kitakyushu, a city in southern Japan, which is a frontrunner city in urban sustainability with much know-how regarding cleaner production and waste management [23]. Since the establishment of Yahata Steel Works in 1901, the heavy and chemical industries of this city in northern Kyushu have led the economic growth of the city [24]. In the decades following World War II, the city of Kitakyushu in southern Japan gained an international reputation for its steel production [25]. The city was built for, and around, its industrial structure; the housing accommodated the labour force of the new industry [26]. However, as these industries lead to higher income, and house ownership was culturally and institutionally idealised in Japan [27], the city expanded horizontally; people started to build new houses in the hillsides and suburbs of Kitakyushu. In the 1980s, the steel industry was past its heyday of the 1960s, and the local government took a more central role in the transition to environmental industries and cleaner areas [23], introducing policies and programs in the early 1990s to change the city's industrial structure into that of an eco-town [26]. This was the beginning of an urban sustainability transition with experiments and initiatives balancing and reinforcing it, which makes Kitakyushu a frontier city in urban sustainability, hailed by international and national institutions [23]. The city's architecture dates from the heyday of Kitakyushu's steel industry, as most buildings are midrise tenant buildings, but the passage of time has given these buildings a worn look, i.e., these buildings have corrugated iron roofs and walls and do not show signs of exterior maintenance [28]. As 
the standardisation of safety, comfort, convenience, and cleanliness embedded in codes and standards is reproduced in the built environment and in people's expectations of what an "ideal home" should be [29], especially given Japan's postwar economic quality-oriented growth [6], many of these houses are considered to be obsolete. Kitakyushu has a renovation culture whereby communities reclaim abandoned houses in the city centre, some of which are over 100 years old [28]. At the same time, new residential development is still taking place in suburban areas, which is observed in other cities in Japan. In general, for Japan, the mechanisms behind vacancies and urban shrinkage are more related to demographic changes and urban sprawl [9], neoliberal urban housing policies, and changes in people's lifestyle [10]. In other Western countries, urban shrinkage is commonly interpreted as a consequence of a decline in local industries (for example, the rustbelts in the USA and Northern England) [30] or as the result of a political regime change, as in postsocialist Europe [31]. The city of Kitakyushu seems to be a hybrid result of both of these "historical trajectories," where the spatial distribution of vacancies in one district can be attributed to a local industry decline, whereas another district seems to reflect changes in lifestyles and cultural housing norms, and standards of cleanliness and safety, comfort, and convenience in particular. For policymakers and industry, it is pivotal to understand the consequences of an Industry 2.0 model (mass production on assembly lines), which was the backbone of Kitakyushu's economy for almost the whole of the 20th century, to an industry 4.0 model (digitalisation, artificial intelligence), which implies a demand for a new type of labour pool. The industrial labour force became more "obsolete" in this local industry decline. By applying housing adjustment theories, this manuscript will explain the impact of economic structural change on the housing norms, which on their turn have an impact on the demographic and built environment patterns. As the current housing conditions of some districts are more characterised by this change, each district has a different housing metabolism and requires a different circular economy strategy. This makes Kitakyushu an excellent case study not only to analyse the complexities of the urban housing metabolism, but also to prove the importance of designing a place-sensitive, social, circular built environment.

\subsection{Political-Industrial Ecology: From Problem to Solution, and from Theory to Practice}

To fully understand the metabolism of housing, we believe a pragmatic combination of industrial and political ecology-based approaches is needed. At first sight, the approaches, methods, and perspectives of political and industrial ecology might appear incompatible, but Newell and Cousins (2015) introduced a political-industrial ecology approach, which has proven to be a viable basis to assess the sustainability of urban systems [32].

While political and industrial ecology share urban metabolism as a common research interest, their approach to it is different. Some scholars, mainly from the field of geography, describe political ecology as a subfield examining the sociopolitical dimensions of the flows, exchanges, and transformations within an economy, while industrial ecology attempts to measure and visualise the incoming and outgoing flows or accumulation of stocks as precisely as possible [33]. This could lead to the interpretation that industrial ecology describes the patterns, and political ecology deciphers why these patterns happen; furthermore, the former applies quantitative assessments while the latter is also open to qualitative approaches. However, industrial ecology, like political ecology, has no stand-alone definition and draws principles, tools, and methods from other disciplines like engineering and economics. The boundary between political and industrial ecology, especially for the study of urban metabolism, is very vague [32-35], which calls for a more integrated approach and perhaps even a refusal to label those tools related to industrial ecology and those related to political ecology. Industrial ecology also utilises qualitative data and examines social dimensions, for instance, to understand the stakeholder processes in industrial symbiosis [36]. The Vienna School of socioeconomic metabolism especially looked beyond quantitative accounts to understand how historical processes have shaped stock-flow trajectories [37]. In addition, Newell and Cousins (2015) criticised industrial ecology for missing a spatial and political dimension, and infused some "spatiality" into the field [32]. Although earlier built material stock studies included spatiality as integral [21,38], the apolitical dimension is still 
a critique. Nevertheless, industrial ecology is one of the schools at the root of the circular economy [11] and not only provides data and descriptive accounts, but also contributes to testing the impact and feasibility of solutions and strategies. Pomponi and Moncaster (2017) emphasised the need for a multidimensional approach in research and design in the built environment [7]. Hence, this article revisits the theoretical considerations of political-industrial ecology [32-35]. For the remainder of this paper, the political ecology component is the system science that critically analyses the roots and context of the current problem (vacant houses) as well as barriers to and opportunities for social transition. Pomponi and Moncaster (2017) called for a behavioural dimension. This manuscript addresses this by integrating well-established concepts of consumer studies and the housing adjustment theories. The underutilisation of a house, or the quality of material stock use, is not only a result of technical factors, but also the result of social factors and specific user behaviour. According to Morris and Winter (1975), homeowners assess the conditions of the house with the help of norms [19]. If the housing conditions do not comply with these norms, a housing need deficit will occur and can lead to an adjustment, like renovation, expansion, or moving out, unless the constraints (e.g., income) are too high. Hence, in the political ecology component, we look at the impact of political, social, and economic factors on these housing norms. The understanding of these housing norms is also used to inspire the quantitative (industrial ecology) part of this research.

The industrial ecology component of this approach is system science, which provides solutions for the future and data on the feasibility of these solutions. Combined into a theory of political-industrial ecology, they will function as the theoretical basis for this article, which seeks to integrate different perspectives into a holistic critical lens.

\subsection{Adding a Spatial and Temporal Perspective on the Circular Built Environment}

The integration of spatial analysis, typically for disciplines like geography, can be increasingly observed in industrial ecology research. Understanding the spatial patterns of urban metabolism not only leads to a holistic view of a city as a system, but also acknowledges the uniqueness of every urban system. Place-sensitive data-quantitative and qualitative—and analyses and calculations can help us to better understand why products, programs, and ideas lead to success or failure in one place but not in another, and can help us to find city-specific circular models [12]. In industrial ecology, defining the system boundaries, i.e., at which level a study can be conducted (local, national, regional, or global), is one prerequisite of many tools, such as life cycle assessment (LCA) and material flow analysis (MFA). In this manuscript, the boundaries equal the municipal boundaries of Kitakyushu. Although some materials require more global circular strategies, like rare metals that are mined and processed in a few places across the world, building materials are widely available; building materials mostly reflect local availability as well know-how, national building standards, and other local characteristics because the construction and use of houses are mediated through local people $[39,40]$. Hence, it seems appropriate to propose local circular strategies for the existing building material stocks and flows in a city, rather than to integrate a wider and more global economy. Industrial ecology is starting to encourage spatially explicit analysis rather than mere statistical analysis without a spatial dimension because the former provides more contextual insights that can help policymakers and other stakeholders to better understand and manage their cities and the stocked capital [13]. For instance, a spatial analysis of the material stock in Padua, Italy displayed an uneven spatial distribution of building materials; whereas the historical centre has "old stock" with a high historical value, the suburbs are more prone to continuous urban renewal processes [13]. This insight can help the policymakers of Padua to decide to look into urban mining for the suburbs of Padua, and to look into the tensions between cultural preservation and other sustainability goals, like alternative and reduced energy use and spatial justice [41], which can be in turn used for remodelling the older parts of the city [42]. The 4D-GIS analysis, for instance, which was developed by Tanikawa and his colleagues and quantifies and locates construction material stocks over time at municipal and national levels, has since been widely used in case studies elsewhere [14]. In other words, they integrated a temporal perspective into the GIS 
tool, which locates the distribution of the material stock in a system, to track the spatial and temporal patterns of material stock over time [14]. This method gives insights into the average building lifetime of stock in various districts of a city, which can be used as a parameter for predicting the outflow of demolition waste, and, consequently, can predict opportunities for urban mining that add value to the economy, or be used to understand when renovation is needed based on building quality and lifespan [43].

\section{Materials and Methods}

The empirical research that provides the basis for this article is built on a mixed-methods approach. It combines a quantitative assessment using GIS analysis and spatial statistics, and a qualitative assessment combining photo, news, and document analysis. The mixed methods approach also reflects the versatility of a theory of political-industrial ecology, which serves as the basis for this research. Furthermore, the research uses an adapted version of the model proposed by Wuyts et al. (2019) to evaluate the status of the existing housing stock and to derive policy recommendations.

The model proposed by Wuyts et al. (2019) successfully provides a simple taxonomy to categorise building obsolescence in support of a circular or material stock-type society. However, to further assess possible circular strategies for the problem of vacant houses, more subcategories are needed. Therefore, we added the idea of dead and hibernating stock to the initial model (Figure 1). In this regard, dead stock means stock that likely cannot be sold for the service for which it was intended and for which storage results in (high) social costs, while hibernating stock still has the potential to serve society again in the purpose for which it was intended. Circular strategies for hibernating housing stock centre on reclaiming, which could involve renovation, retrofitting, and adapting different marketing strategies. If a house is in a state of disrepair or is obsolete according to the current norms and standards, it is dead stock. In business, dead stock refers to the amount of a product that a company or institution has bought or made but is unable to sell, and storing it is costly. A vacant house could be considered as dead stock when the costs for keeping it are high, and if it is unlikely the house will get sold, as in the case of permanent stagnation such as in shrinking cities. The recommendation is to deconstruct the house and "mine" the materials or components, because such houses can cause health risks related to bad living quality (individual risks), social disorder (neighbourhood risks), and compact city planning (urban management risks) [6]. Urban mining refers to the recovery of "materials accumulated in the urban environment, which were not specifically designed for recycling or reuse" [22].

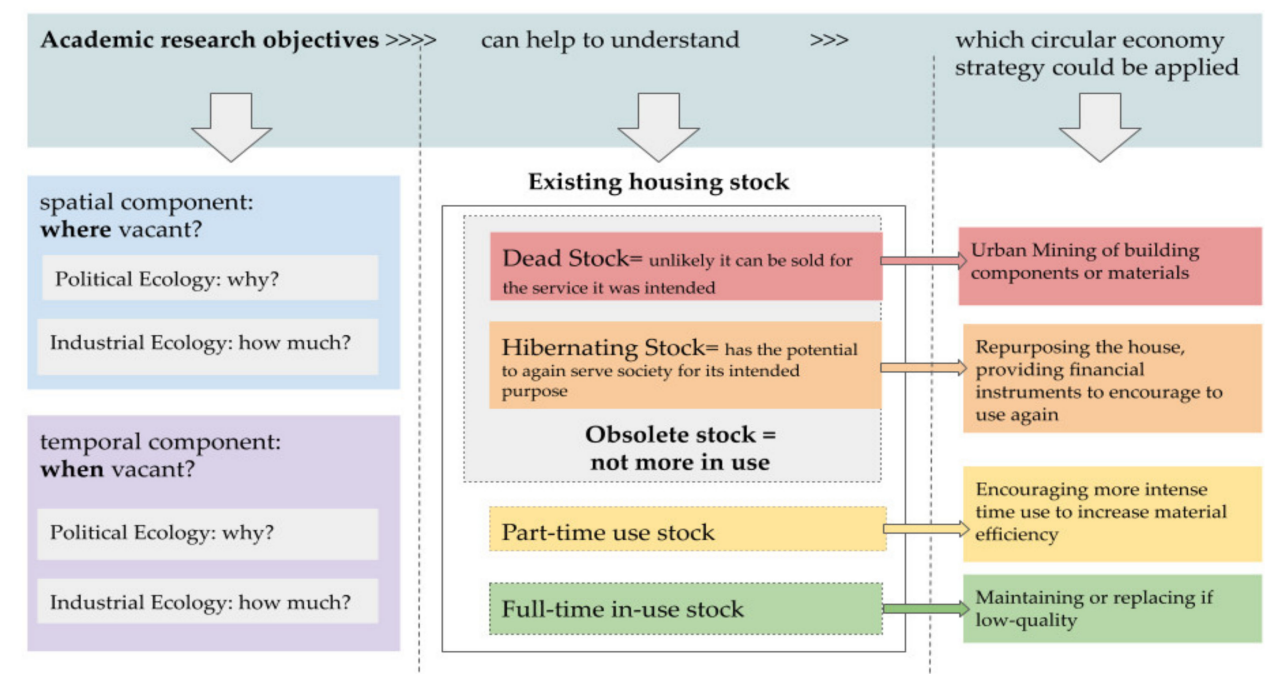

Figure 1. Circular economy concerning vacant houses—the adapted heuristic model from Wuyts et al. 2019 for researchers and policymakers. 
The spatial and temporal components presented in Figure 1 can help us to understand the why, where, and how much of obsolete stock, to estimate its potential, and to predict why and when these material stocks became obsolete. However, as part of the temporal component of the model, the historical processes and the meaning associated with the social practice of "using a house" have to be analysed to identify the impact of the ideologies dictating industrial and housing policy in Kitakyushu. In other words, not only should material inputs be studied, but also nontechnical factors, like needs in terms of human resources $[44,45]$ and market regulations $[45,46]$, as well as the dynamics behind consumption, like changes in norms and codes of social practices over time [47,48]. To acknowledge this, the model outlined in Figure 1 is complemented by an overview of the relationship between domains of practices, built material stock, jobs, and people (Figure 2).

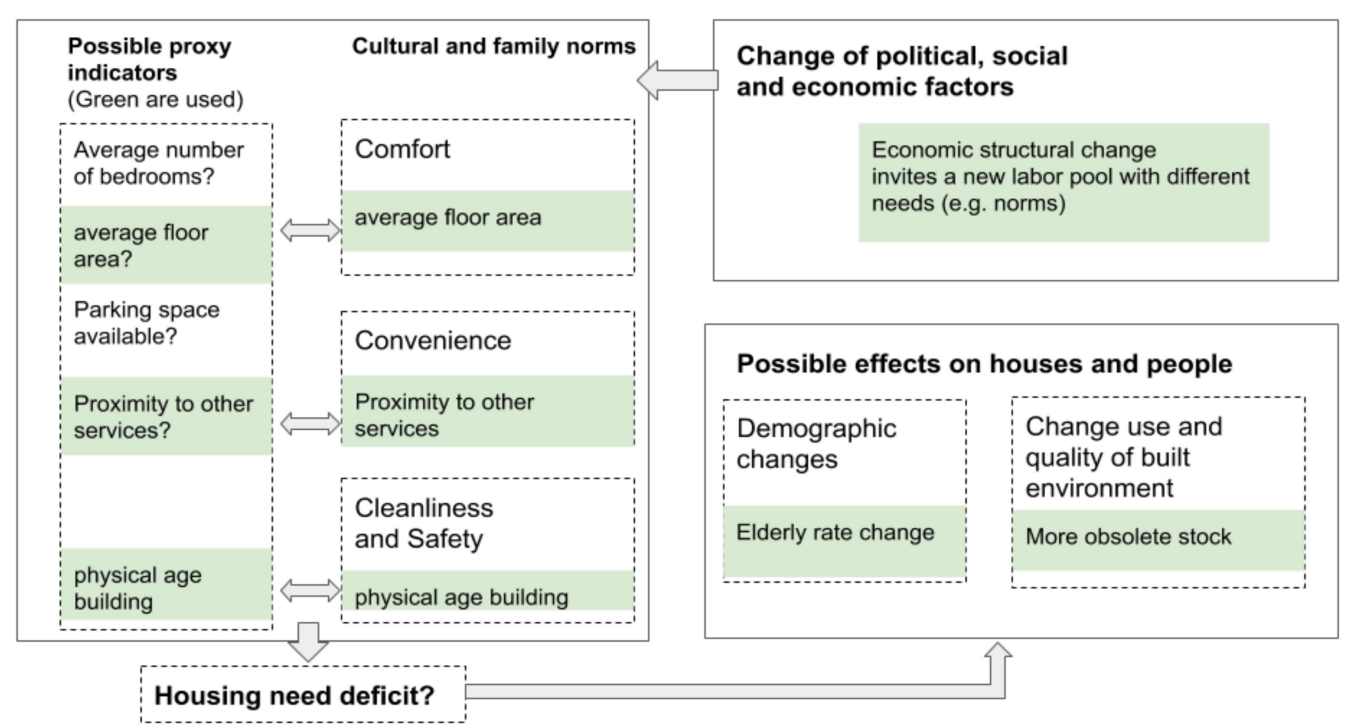

Figure 2. Schematic overview of the relationship between norms, built material stock and people, and changes in political, social, and economic factors. The indicators serve as examples of how to measure the case of a house.

Moreover, it must be stressed that standards and norms are nurtured by the values and form of organisation of a society and therefore are continuously changing. Having said that, this change can be driven by powerful actors within or, in some cases, even outside of the society. For cases of housing, this means that stakeholders, like policymakers or the building industry, may intend to change the standards and norms to their benefit. An example in housing is the standardisation of qualities like safety, comfort, convenience, and cleanliness. Moreover, current narratives are commonly the result of path dependencies, causing difficulties in renegotiating them [29]. Taking this into account with regard to the disposable house culture in postwar Japan, building standard codes could guide decisions about which houses are delayed obsolete (i.e., houses that are obsolete in terms of social norms but still in circulation [6] according to the local survey (Table 1) and the estimation based on our primary data collection (Table 5)) and which are not. For example, when citizens look for new houses, they are advised to get houses built after 1981 because they have been built following stricter regulations regarding resistance to earthquakes. Figure 2 gives a schematic overview of the studied norms influencing everyday practices after Shove (2003); "comfort, cleanliness, and convenience" provides indicators to operationalise them and demonstrates their relationship and effect on the built material stock and people, but also the impact of political, social and economic factors, and economic structural change in particular, on these norms. The concept of housing adjustment theories, as proposed by Morris and Winter (1975), is integrated in this figure [19]. 
Table 1. Features of the two districts of primary data collection.

\begin{tabular}{cl}
\hline District & \multicolumn{1}{c}{ Description } \\
\hline Yawata Higashi Ward & $\begin{array}{l}\text { Residential area. Samples were taken in neighbourhoods on slopes near the } \\
\text { industrial area, which was the industrial centre, as well as in housing blocks } \\
\text { with narrow streets. Because of the proximity to the central city area, the } \\
\text { density of houses is relatively high, and the rate of poorly approachable } \\
\text { houses is high. }\end{array}$ \\
\hline Wakamatsu & $\begin{array}{l}\text { Reclaimed city area formed by the Wakamatsu Construction Port Project in } \\
\text { the Late Meiji Era. Although the roads are relatively wide (compared with } \\
\text { Yawata Higashi), the housing density is high, because of the average small } \\
\text { house size. Many houses are old according to Japanese standards. }\end{array}$ \\
\hline
\end{tabular}

\subsection{Quantitative Assessment}

For the quantitative assessment of the spatial patterns behind vacancy, this study looked at GIS data from two sources: the survey from the local government conducted in 2014-2015 [49,50] and primary data collection on site. Regarding the local survey conducted in 2014-2015, the local government used visual data to count and categorise the vacant houses according to deterioration degree or risk $[49,50]$. The risks were assessed based on location characteristics (neighbourhood norms, e.g., inclination of the closest road) and physical appearance (quality norms, e.g., uncontrolled growth of plants at the door). As staff of the local government conducted the survey and are the sole determinants of this risk assessment, these data have some built-in problems. Whereas neighbourhood norms involve subjective orientations toward basically objective matters, the latter is about subjective matters [19]. In addition, the agenda of the local government for this survey was not to support the building of a material stock-type society or circular built environment.

Concerning the second data source, over the last few years, Tanikawa and his team built a 4D-GIS dataset for Kitakyushu to investigate previous material stock analysis, complemented by insights into the local history of the city. More concretely, Tanikawa and his team digitised and georeferenced maps for the years 1986, 1995, 2000, 2005, 2010, and 2014 to calculate the material stock, as proposed by Tanikawa et al. (2009), and divided them into in-use-stock and obsolete stock. The first step was primary data collection on site. In October and November 2019, field surveys were conducted in the sampled neighbourhoods, which were chosen based on their different historical trajectories. Table 1 describes the features of the two main wards (or districts) where the team collected primary data collection and some difficulties with the primary data collection. The team counted temporary and permanent vacant houses. A 360-degree camera was put on the roof of a car to take pictures while driving in the target area. In addition, a survey was done by foot in areas inaccessible to cars. When the house looked in good shape and/or a sign indicating it was to rent or for sale was visible, a label of temporarily vacant was assigned to the house. When a house was in bad condition (for example, with significant damage to the outer walls, roofs, and windows), the label of permanent obsolescence was assigned. In total, of the around 2000 houses assessed, around 90 were considered obsolete. The information was digitised and added to the GIS database.

Secondly, a factor analysis (multiple regression analysis) was conducted to understand which explanatory variables were significant. These factors comply with housing adjustment theories [19] on which are the housing needs that homeowners can have, as well as the political, social, and economic factors and constraints (Table 2). A house can end up in a vacant state if, for example, the housing market conditions change, the economic structure changes, and/or if one or more norms change and constraints can be overcome. An example of a constraint is the limit of expanding a house when a family changes, due to childbearing for example, and more space is required. This could then lead to the family's choice to move from this house. To simplify the factor analysis, input variables were chosen on the basis of whether they could be derived from the database and considering the local 
history of the districts and Kitakyushu. For convenience, we tested several input variables that are also used in the location optimization plan of Kitakyushu [51] to synchronise better with policy makers.

Table 2. Choice of factors, sorted according to the housing adjustment framework [6,7].

\begin{tabular}{|c|c|c|c|}
\hline $\begin{array}{l}\text { Housing Need Type or } \\
\text { Cultural Norm Type }\end{array}$ & Norm & Input Variable (Factor) & $\begin{array}{l}\text { Description and More Explanation } \\
\text { about the Input Variable }\end{array}$ \\
\hline Space Norms & Comfort & Floor Area & Floor area of the building $\left(\mathrm{m}^{2}\right)$ \\
\hline Tenure Norms & & No Input Variables & $\begin{array}{l}\text { Data about home ownership cannot be } \\
\text { retrieved from the current database. }\end{array}$ \\
\hline Structure-Type Norms & & No Input Variables & $\begin{array}{l}\text { This manuscript focuses upon detached } \\
\text { single family type housing. }\end{array}$ \\
\hline Quality Norms & $\begin{array}{l}\text { Cleanliness } \\
\text { and Safety }\end{array}$ & $\begin{array}{l}\text { Building Age } \\
\text { Flagpole Area }\end{array}$ & $\begin{array}{l}\text { Building age }=2018-\text { construction year } \\
\text { Flagpole = houses with a centre of } \\
\text { gravity of the building at least } 10 \mathrm{~m} \\
\text { away from the road are assumed to be } \\
\text { "flagpole grounds" = } 1\end{array}$ \\
\hline \multirow[t]{2}{*}{ Neighbourhood Norms } & Convenience & $\begin{array}{c}\text { Near Station } 1 \\
\text { Near Bus Stop } 2 \\
\text { Near Hospital } 2 \\
\text { Near Welfare Facility } 2 \\
\text { Near Elementary } \\
\text { School 1 } \\
\text { Near Industrial Zone } 1 \\
\text { Nearest Road Width } \\
\text { Housing Density } \\
\text { Inclination }\end{array}$ & $\begin{array}{l}\text { Boolean Variables } \\
{ }^{1} \text { Within } 500 \mathrm{~m}: 1 \\
2 \text { Within } 300 \mathrm{~m}: 1 \\
\text { These choices are based on the } \\
\text { Kitakyushu Location Optimization } \\
\text { Plan [50]. } \\
\text { Nearest road width = the width of the } \\
\text { road closest to the building (m) } \\
\text { Housing density = average number of } \\
\text { buildings per } \mathrm{km}^{2} \text {. } \\
\text { Inclination = average value of } \\
\text { inclination data closest to the building } \\
\text { for each } 100-\mathrm{m} \text { mesh }\left(^{\circ}\right)\end{array}$ \\
\hline & Diversity & $\begin{array}{l}\text { Elderly Single } \\
\text { Household Ratio }\end{array}$ & $\begin{array}{l}\text { Percentage of households } 65 \text { years old } \\
\text { or older in this housing block }\end{array}$ \\
\hline
\end{tabular}

After the factor analysis, the significant variables were put into the estimation model of the distribution of housing. The model can be described by Equation (1):

$$
y(i)=a(i) * x(i)+b,
$$

where y: vacant house ratio for every 100-m mesh, $x$ (i): explanatory variable, a (i): regression coefficient, b: constant. The variables are chosen based on the Kitakyushu City Location Normalisation Plan [51]. The validity of the model is verified by comparing the number of vacant houses in each administrative district according to the local survey on the vacant houses conducted by Kitakyushu City in the period 2014-2015 [49,50]. The preliminary results are used to visualise which places accounted for a higher percentage of obsolete stock. In addition, the study combined these maps with data about land zoning and housing (and their attribute data), and local statistics about the age of the population for several districts and neighbourhoods [52,53]. Lastly, the material stock of detached houses was calculated for every 100-m mesh. A 100-m mesh is a mesh-based polygon of $100 \mathrm{~m}$ by $100 \mathrm{~m}$. The calculation followed the well-established approach proposed by Tanikawa et al. (2009) and used method and material intensity coefficients for houses made with nine categories of stock-building materials. The materials covered in the analysis are expressed in millions of tonnes. The material intensity coefficient table is an updated version of the article by Tanikawa et al. (2009). Hence, the obsolete stock was estimated by multiplying the total material stock by the vacancy rate. The in-use stock was estimated by subtracting the obsolete stock from the total material stock. 


\subsection{Qualitative Assessment}

A qualitative assessment was carried out to prepare the quantitative assessment and to validate and complement its results. In the first phase, neighbourhoods or larger districts that have unique historical trajectories for primary data collection were identified. The necessary data were collected during field visits (July 2018-October 2019) and were drawn from observations and the analysis of historical photographs. In addition, a desktop-based analysis of national and local policy reports on the construction and demolition of buildings was carried out to obtain further information on the historical metabolism of the housing stock in the neighbourhoods. Last, a media analysis of local news was undertaken to bridge data gaps and gain insight into the societal discourse regarding the demolition and vacancy of residential buildings. For the second phase, the adapted model proposed by Wuyts et al. (2019) took centre stage. The results of the first round of the quantitative and qualitative assessment were used to classify the existing housing stock according to the ratings proposed in Figure 1 and to confirm the role that the domains of practice play (outlined in Figure 2).

\section{Results}

Section 3.1 introduces the case study and presents the first round of findings on the city level. Section 3.2 zooms in on three selected districts and shows through a spatial-temporal lens that one impulse, the changing industrial structure, can have very different effects in different neighbourhoods. Furthermore, it demonstrates the need for local and place-sensitive strategies within a city to tackle the dynamics driven by global trends.

\subsection{Setting the Scene}

Whereas the national residential vacancy rate is $13.6 \%$, the residential vacancy rate for Kitakyushu is $16.3 \%$, according to the 2018 Housing and Land Survey of Japan [3]. According to calculations based on the national survey, Kitakyushu counts 81,600 vacant dwellings, of which 24,800 are detached houses, 5100 are tenement houses, 51,500 are apartments, and 200 are of other classification. In 2018, only $9 \%$ of these detached houses were offered for rent and only $18 \%$ were for sale. While $95 \%$ of the vacant detached housing stock is made from wood, only $12 \%$ of the vacant apartments are made from wood. The government classified the vacant houses as high risk, medium risk, low risk, or no danger $[49,50]$. All risky vacant houses are dead stock and should be urban mined, while the houses classified as "no danger" are hibernating stock and can be redeveloped to serve the people in Kitakyushu. The survey classified 7296 vacant houses, of which 3397 cases (46.6\%) were "risky". Table 3 displays the numbers for Kitakyushu's seven districts.

Table 3. Assessment of the vacant houses counted in 2014-2015 by the local government of Kitakyushu according to degree of risk. All risky houses are dead stock, while the vacant houses without risk are hibernating stock. The percentage is the number of vacant houses compared to total vacant houses in this ward. Source: $[49,50]$.

\begin{tabular}{cccccc}
\hline & Dead Stock & \multicolumn{3}{c}{$\begin{array}{c}\text { Hibernating } \\
\text { Stock }\end{array}$} \\
\hline Ward & $\begin{array}{c}\text { High Risk } \\
\text { (in \%) }\end{array}$ & $\begin{array}{c}\text { Medium Risk } \\
\text { (in \%) }\end{array}$ & $\begin{array}{c}\text { Low Risk } \\
\text { (in \%) }\end{array}$ & $\begin{array}{c}\text { No Danger } \\
\text { (in \%) }\end{array}$ & $\begin{array}{c}\text { Total Vacant } \\
\text { Houses }\end{array}$ \\
\hline Moji & 9.2 & 22.2 & 14.2 & 54.4 & 1573 \\
Kokurakita & 8.7 & 16.8 & 17.7 & 56.8 & 1005 \\
Kokura Minami & 3.1 & 15.5 & 16.7 & 64.7 & 618 \\
Wakamatsu & 9.9 & 14.5 & 25.3 & 50.3 & 736 \\
Yahata Higashi & 12.3 & 23.1 & 21.8 & 42.8 & 1764 \\
Yahata Nishi & 6.3 & 15.4 & 19.9 & 58.4 & 1201 \\
Tobota & 8.8 & 15.8 & 13.8 & 61.7 & 399 \\
Total & 8.9 & 18.9 & 18.8 & 53.4 & 7296 \\
\hline
\end{tabular}


During the primary data collection in 2019, it was observed that neighbourhoods in the Yahatahigashi Ward have a higher vacancy rate, because this is the area with old housing for the labour pool of the industrial heydays. In neighbourhoods that were closer to the main train station, fewer vacant houses were observed. Although the average road is relatively narrow in some of these neighbourhoods, the proximity to the train station and the possibility of redevelopment make it more likely that abandoned houses will be quickly replaced by newer houses.

The factor analysis (Table 4) revealed that the significant factors were the average value of inclination data closest to the building for each 100-m mesh, the building year, the proximity to industrial zoning, and the number of buildings per neighbourhood. Inclination seems to be an important factor. In Japan's disposable house culture, which conveys the observation that houses are seen as liabilities and not treated as assets, demolition costs are high, because often the roads in residential areas on steeper slopes are composed of steps, which restricts the access of trucks and heavy equipment to enter and dismantle. In addition, these areas are not attractive for car owners, so it is unlikely these houses will be chosen by potential buyers.

Table 4. Outputs of the regression analysis, ${ }^{*}: 0.01<p<0.05,{ }^{* *}: p<0.01$. The explanatory variables are based on the variables used in Kitakyushu City Location Optimisation Plan [51].

\begin{tabular}{ccccc}
\hline Explanatory Variable & $\begin{array}{c}\text { Regression } \\
\text { Coefficient (RC) }\end{array}$ & Adjusted RC & T Value & Adjusted T Value \\
\hline (Constant) & -18.2699 & -8.7 & -0.031 & $-7.326^{* *}$ \\
Inclination & 0.0562 & 0.0554 & $2.501 *$ & $2.612^{* *}$ \\
Nearest Road Width & -0.1601 & -0.1666 & -1.374 & -1.464 \\
Flagpole & 0.2535 & & 0.754 & \\
Floor Area & -0.0017 & & -0.552 & $1.727^{*}$ \\
Housing Density & 0.0005 & 0.004 & $2.139 *$ & $2.154^{* *}$ \\
Proximity to & 1.5165 & 1.5025 & $2.097^{*}$ & \\
Industrial Zone & -5.1807 & & -1.148 & $2.168^{* *}$ \\
Elderly Single & 0.0412 & 0.0416 & $6.000^{* *}$ & 2.669 \\
Household & 0.757 & 1.1308 & 1.368 & \\
Building Age & 10.5308 & & 0.018 & \\
Proximity to & -0.2508 & & -0.731 & \\
Train Station & 0.9493 & & 1.191 & \\
Proximity to Bus Stop & & & -878 & \\
Proximity to Hospital & -0.3499 & & \\
Proximity to & & &
\end{tabular}

Subsequently, we estimated the vacancy rate for all the areas in Kitakyushu by using these factors (Table 5), which will be discussed further in Section 3.2.

Table 6 presents the results of the estimated obsolete and in-use material stock for detached houses. Regarding the spatial distribution on a district level, a higher amount of obsolete stock was observed in Yahatahigashi, Moji, and Wakamatsu, neighbourhoods where houses are built on high slopes and close to each other. This manuscript uses the classification of the city road certified standards in Japan. A flat area means an area with roads with an average slope of $2.86^{\circ}$ or less; a "less flat area" means an area with roads with an average slope between $2.86^{\circ}$ and $5.71^{\circ}$, a "sloped area" means an area of roads with an average slope between $5.71^{\circ}$ and $9.09^{\circ}$, and a "steep slope area" means an area with roads with an average slope higher than $9.09^{\circ}$. 
Table 5. Comparing studies by the local government and the results of this study. $\left.{ }^{*}\right)$ Between total vacant housing (dead and hibernating stock) in local government survey and our model (**). Between risky vacant housing (only dead stock) and our model.

\begin{tabular}{cccccc}
\hline \multicolumn{7}{c}{ Kitakyushu's Survey } & Our Survey & & \\
\hline Ward & $\begin{array}{c}\text { Risky Vacant } \\
\text { Houses }\end{array}$ & $\begin{array}{c}\text { Total Vacant } \\
\text { Houses }\end{array}$ & & Divergence * & Divergence ** \\
\hline Moji & 686 & 1573 & 1059 & $148 \%$ & $65 \%$ \\
Kokurakita & 434 & 1005 & 375 & $268 \%$ & $116 \%$ \\
Kokura Minami & 218 & 618 & 331 & $187 \%$ & $66 \%$ \\
Wakamatsu & 366 & 736 & 650 & $113 \%$ & $56 \%$ \\
Yahata Higashi & 1009 & 1764 & 1009 & $175 \%$ & $100 \%$ \\
Yahata Nishi & 239 & 1201 & 462 & $260 \%$ & $52 \%$ \\
Tobota & 153 & 399 & 245 & $163 \%$ & $62 \%$ \\
Total & 3400 & 7296 & 4132 & $177 \%$ & $82 \%$ \\
\hline
\end{tabular}

Table 6. Estimated obsolete and in-use material stock for detached houses (in millions of tonnes). Usage is the percentage of material stock that is in use.

\begin{tabular}{ccccc}
\hline Area & Obsolete & In-Use & Total & Usage (\%) \\
\hline Kitakyushu (Total) & 0.329 & 17.754 & 18.082 & 98.2 \\
Flat Area & 0.022 & 8.378 & 8.400 & 99.7 \\
Less Flat Area & 0.026 & 4.271 & 4.297 & 99.4 \\
Sloped Area & 0.057 & 2.415 & 2.471 & 97.7 \\
Steep Slope Area & 0.224 & 2.690 & 2.914 & 92.3 \\
\hline
\end{tabular}

\subsection{Zooming In: A Spatial-Temporal Analysis on the Level of Districts}

The vacancies do not occur in the same quantity and quality in each district or neighbourhood. To understand the spatial distribution of vacant housing, we selected for further assessment Yahatahigashi, Yahatanishi, and Kokurakita, three dynamic districts with an interesting historical background and a high number of vacant houses according to a first estimation model and local survey results $[49,50]$. Figure 3 displays the seven districts of Kitakyushu, important railroads and highways, and designated industrial zones.

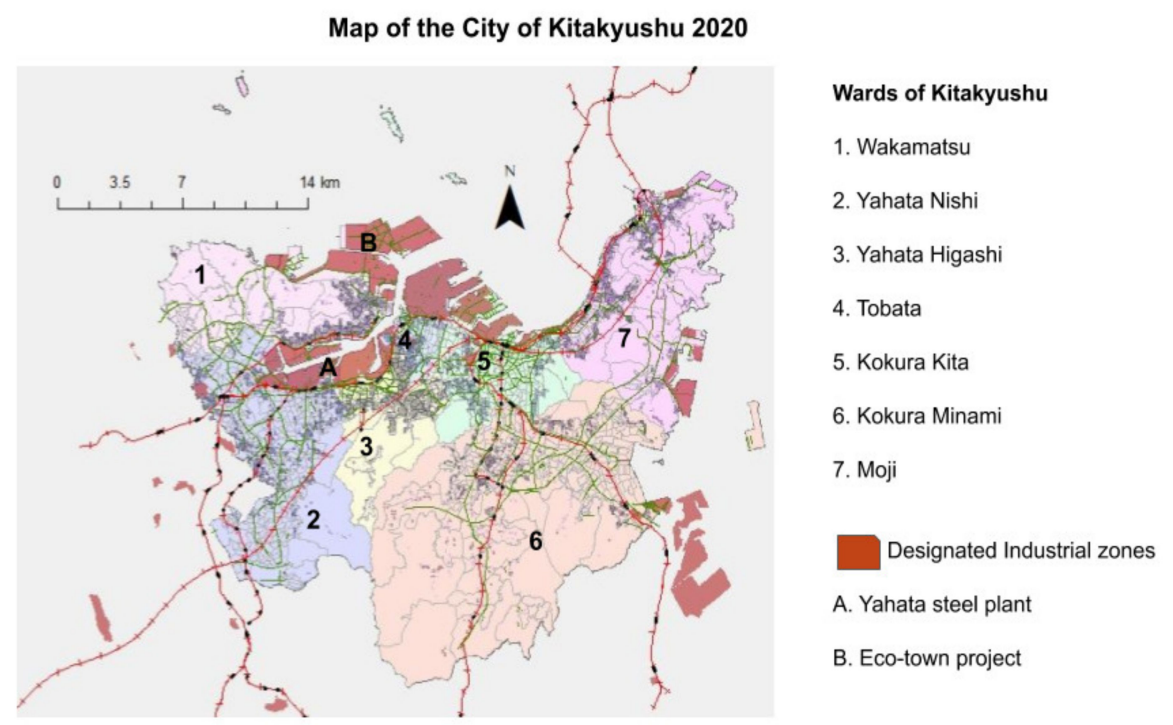

Figure 3. The districts of Kitakyushu designated as industrial zones and roads. GIS data source: [52]. 
As Figure 2 explains, demographic changes and the accumulation of vacancies are consequences of the perception of the current housing conditions as obsolete in terms of norms and standards. The study of the effect of housing norms on people is also pivotal to the design of a social circular economy because the main driver of this transition is to serve society as efficiently as possible. Hence, this manuscript investigates demographic and vacancy patterns and the narrative behind these changes. Smaller cities in postgrowth Japan tend to have different demographic and vacancy patterns than megacities like Tokyo [5]. In bigger cities, suburbs tend to have a higher number of vacant houses, whereas, in smaller cities, an increase in vacant houses can be found in the city centre. Since the 1990s, attractive facilities and services, like department stores, banks, hospitals, and city halls, have relocated to suburban locations [5]. In the meantime, highways have been established in the suburbs, making travel by car increasingly convenient and comfortable in cities like Kitakyushu. Kitakyushu demonstrates an interplay of different factors, which are stronger in some districts than in others, because of place-specific historical trajectories of norms and other factors like economic structural changes.

Of the three districts studied, Yahatahigashi shows a negative trend in demographic patterns for the last three decades, and a higher percentage of empty houses, which seem to be delayed obsolete. Yahatahigashi district is situated around the old Yawata steel factory plants and counts many hilly areas with a high housing density. The slopes are steep, but people built there back in the heyday of the steel factory, to be close to their work. Codes of safety, cleanliness, comfort, and convenience were different from today. Figure $4 \mathrm{~b}$ shows a much bigger contrast compared with Figure $4 \mathrm{a}$; the child population dropped by more than $50 \%$, and there was a significant outflow of young people. While the histogram for 1989 seems balanced, the histogram for 2019 shows the opposite pattern. This can be explained by the fact that the heydays are over. Kitakyushu is investing in Industry 4.0. Consequently, manufacturing skills became obsolete. Even if the labour force gets retrained for Industry 4.0, there is not room for everyone because Industry 2.0 required a larger labour force than is needed in Industry 4.0 [54,55]. Hence, Yahatahigashi's population is shrinking rapidly, and it is no surprise that this is one of the districts most altered by vacant housing. Economic structural change often causes the displacement of long-term residents and a process of "forgetting" [55], but hilly districts like Yahatahigashi do not comply with the standards and codes of comfort, safety, and convenience of the new labour pool; the effect is that the older, long-term residents stayed and became elderly, while the younger labour force, with their manufacturing skills, moved away. The vacancies, especially in this district, are a combination of local industry decline and a lock-in effect that accelerates both the rise in vacancies and the outflow of young people. Hence, most vacant houses can be considered as dead stock because new families will not purchase these houses as they do not meet their norms. A risk is that these houses will become slum areas for the elderly who stayed behind, or those who do not have the income to migrate or replace the house with a new one. From a social circular economy perspective, deconstruction and urban mining of the secondary resources would be the best option. Ideally, the profit from these operations would be invested into schemes to provide better housing conditions for the long-term residents. 


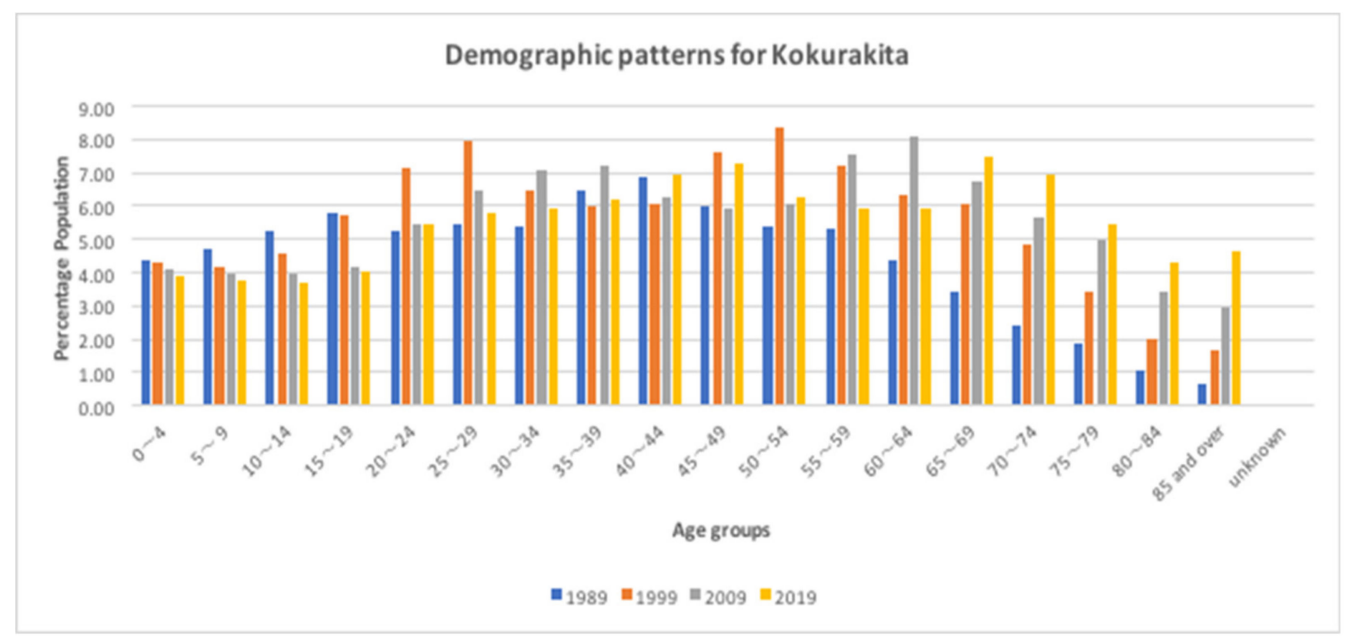

(a)

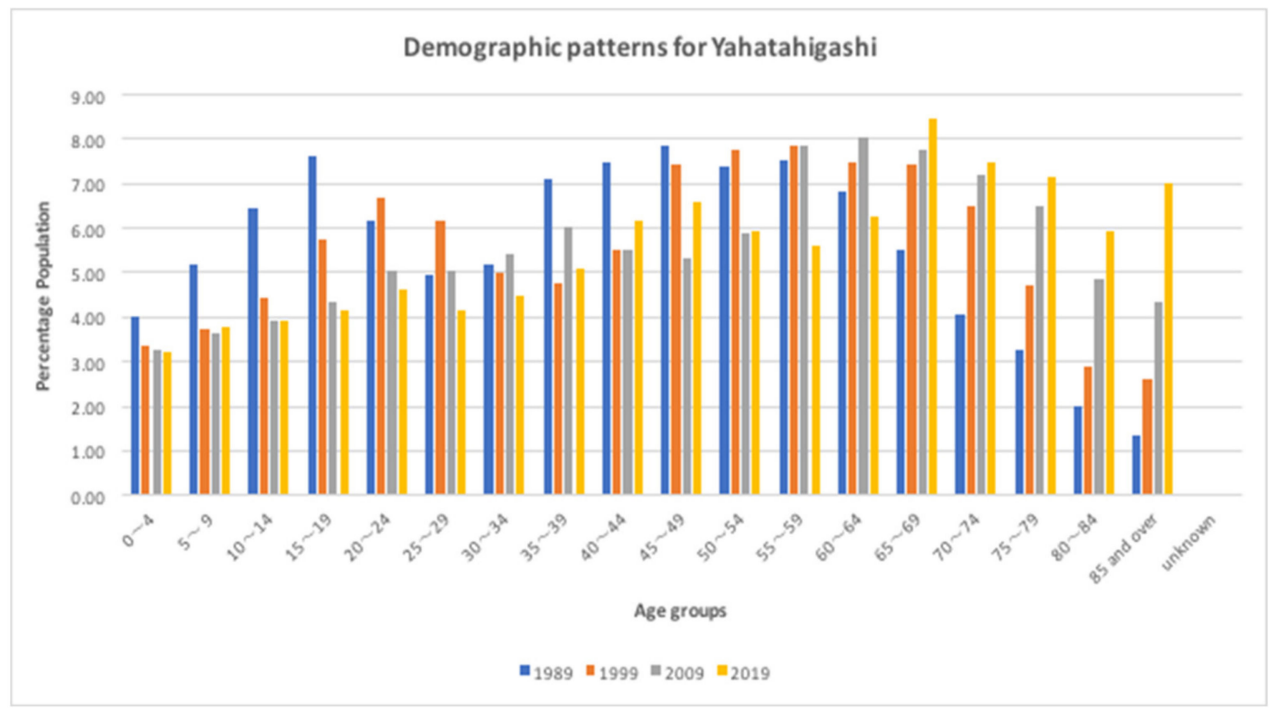

(b)

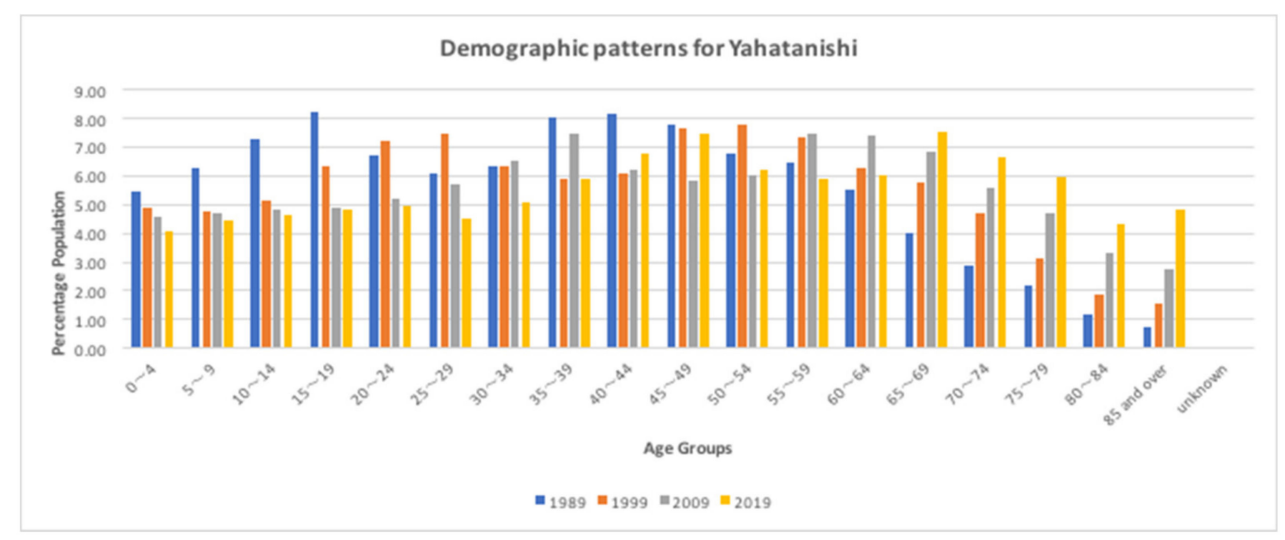

(c)

Figure 4. Demographic patterns for three selected districts for 1989-2019. The statistics were recorded on September 30, except for 2019, when they were recorded on March 31. (a) Kokurakita, (b) Yahatahigashi, (c) Yahatanishi. Data source: [52]. 
Both the centrally located Kokurakita and the peri-urban Yahatanishi seem to have more hibernating stock than dead stock based on our observations of the housing and demographic patterns. The Kokurita district can be considered to be a city centre as it is where the high-speed train stops, and it has old neighbourhoods with narrow streets that do not allow for a high amount of redevelopment to accommodate new standards and codes of convenience (for example, lack of space for creating more parking spaces for cars). In this area, NGOs and small enterprises that are reclaiming and repurposing vacant houses into galleries, offices, and so on, like the Kitakyushu Renovation School, are active. These activities also attract tech-savvy and creative people, who are hailed in Industry 4.0 visions. This small movement of young people recognizes the historical value of these buildings. Figure 4a shows a decline in younger age groups, which stabilized at the beginning of this century, with the sharpest decline noted for the number of children and the greatest rise seen in the 65-69 age group, which is a nationwide trend in the shrinking Japanese society. Although the current housing does not comply with the norms, this inflow of people has the resources (e.g., skills and income) to overcome the constraints and apply housing adjustments. Therefore, the large number of vacant houses could be considered as hibernating. Social circular economy strategies from the local government could include the availability of housing adjustment grants and fiscal instruments that encourage renovation.

Yahatanishi district has less obsolete stock. This district in the south is a cleaned-up suburban area that is still a commutable distance from the city centre and provides easy access to highways and railroads. This district is less hilly and, by accommodating the new standards of safety, comfort, cleanliness, and convenience, experiences a fast urban renewal process. Although all three districts have been characterised by an outflow of young people in the last few decades, Yahatanishi seems to keep part of its productive and reproductive labour; however, the number of people of reproductive age is decreasing. Figure $4 \mathrm{c}$ shows a slightly more stable situation for this 30 -year time span, which could relate to the revitalisation efforts by the local government in this neighbourhood. From a circular economy perspective, strategies for this district should focus upon encouraging longer use of the same house by implementing higher constraints for demolition and for migration. The vacant housing can be considered hibernating stock that can be 'awakened' by similar strategies.

\section{Discussion}

A look at the contemporary scientific literature shows that vacant houses and their impacts on cities have only recently been studied in Japan. Compared to other urban locations, not much research has been conducted in Japan, and those studies that exist mostly focus on the housing market and urban housing policies [4], related to the urban governance challenges of why the strategies of local governments failed when dealing with vacant housing [10], and on the role of public-private partnerships and civic engagement in revitalising these hibernating material stocks [56]; the studies did not view these subjects from a sustainable materials management perspective. Therefore, although these studies helped us to understand the reasons for housing vacancies in Japan and within cities, they cannot contribute to discussion of political ecology. Regarding the industrial ecology component, and especially the novelty of estimating the amount of obsolete stock, comparison is again difficult. Several scholars developed and applied estimation models of vacancy in Japan, but only at the prefecture and national level [57-59].

Applying the updated model by Wuyts et al. (2019) to a real-world case in Japan has illustrated that, whilst knowledge about causes and consequences as well as policy responses towards shrinkage is fairly developed [4], there is a lack of integration of knowledge from different disciplines related to vacant houses, governance, and the circular urban built environment. Based on their research on the circular built environment, Pomponi and Mancaster (2017) called for a multidimensional approach [7]. Marin and De Meulder (2018) also noted how the multidimensional design of a circular city requires inputs ranging from industrial ecology's quantitative tools to political ecology's criticality to support place-specific circular economy transition [12]. This manuscript presents a practical case that answers this need, showing the insights that industrial ecology can offer. However, the industrial ecology 
component of this study lacks a temporal perspective because the primary data collection was only conducted in 2019. However, the political ecology component compensates for this shortcoming by adding a critical examination of the historical trajectories of Kitakyushu's people, economic structure, and its impact on housing for several districts. This insight helped us to understand in which districts obsolete stock should be considered as dead or hibernating, and to identify a place-specific circular economy strategy for that district.

Notwithstanding, in the process of preparing this study, uncertainties and ideas for policy makers and future research have been unearthed. Section 4.1 discusses the uncertainties of the findings in the industrial ecology component for the case of Kitakyushu. The political ecology component of this research will be discussed in the subsequent subsections. Adhering to the current norms and standards for housing, Section 4.2 explains which neighbourhoods are more favourable and have more successful rehabilitation, and which districts are more fit for urban mining. This subsection adds a critical discussion on the history of the obsolescence of labour skills in Kitakyushu (and the unintended obsolescence of housing) and addresses the need for the integration of the social economy, i.e., an economy that prioritizes the needs of all citizens over a return on investment.

\subsection{Uncertainties in the Spatial Patterns of Obsolete Stock}

Construction material stock studies have started to take uncertainty into consideration $[60,61]$. For example, Tanikawa et al. (2015), in their bottom-up analysis of stock, looked into the reliability of the inventory data, the reliability of the material intensity factors, and the uncertainty in matching an inventory item to its correct material intensity by comparing the figures of several studies for several end-use categories [38]. This section zooms in on a new source of uncertainty: primary data collection to estimate the spatial patterns of vacancies. Section 2 explained that the primary data collection of the local government has a different agenda than the primary data collection by this team. This agenda can influence the subjectivity of the assessment. In addition, the assessments behind both data collections involve quality norms, hence the assessment is subjective and automatically implies errors in data.

When we compare the results of this estimation study with the figures of vacant houses counted by the local survey per district (Table 4), the divergence is relatively high, especially for Kokurakita and Yahatanishi, which are flatter areas. The first district is close to the main train station, which makes this area prone to redevelopment, according to the location optimization plan of the city [51]. The second, which has a lower percentage of obsolete housing stock, is a suburb with a higher inflow of youth and could reflect the fact that this area has neighbourhood and quality norms that are not outdated according to younger families. As our factory analysis integrated neighbourhood and quality norms, this could explain the high divergence. When we compare only the risky vacant houses (as this study only counted houses that are also in a certain state of deterioration), we see a strong divergence for Yahatahigashi, which is the district linked to the steel factory, as well, surprisingly, Kokurakita.

For a district like Yahatanishi that scores low in both comparisons, finding the relevant omitted factors would improve the estimation of vacancy level. However, these omitted variables might not be the explanatory factors for other districts. Hence, we need to zoom in to the district level and study in more detail the dynamics and patterns of people, jobs, wealth, and the built environment (Section 4.2). In addition, future research can focus more locally and select neighbourhoods, examining the housing conditions (including physical geography features), and constraints for users (including wealth and income), and do a marketing study on the housing needs of users and the impact of these needs on the housing consumption and the quality and degree of efficient use. However, such a study would require sensitive and/or nonexistent data on the users.

Another explanation can be found in the differences between assignment criteria used in the different primary data collection. In policy documents, the local government ranks vacant houses on how well they are managed and their cleanliness, age, and location factors, such as road width, house maintenance, the proximity of public transportation, and other provisioning systems. These indicators reflect the new cultural standards and norms of "comfort, cleanliness, convenience" [29], and 
"safety" that have dramatically changed and are ingrained in Japanese institutions and mindset since the Second World War. However, the classification they used in their quantitative data implies that their motivation was to reduce danger and hygiene risks. The agenda of our primary data collection was to look for opportunities for circular economy strategies, not for reducing risks. Notwithstanding, a multidimensional approach is required in the transition toward a circular built environment [7]. Therefore, both data sources can be mobilised to understand the spatial patterns of obsolete stock and to design place-specific circularity strategies. Political ecology and political economy's criticality add the focus on social equity, which is often forgotten or marginalised in circular economy theory and practice [62].

\subsection{Relationships between Jobs, People, and Local House Consumption}

Political economy theorises the cycle of periods of new growth and stagnation in economies through, for example, Kondratieff waves [63], where a new growth phase implies a change in the sectoral and spatial structures of the economy. On a national scale, Kitakyushu is in stagnation; however, looking at the district scale, there is a spatial difference within the city. The districts that accommodate Industry 4.0. and the needs and norms of the labour force for housing face less severe stagnation than the districts that are more locked into Industry 2.0 (Figure 5). Although Industry 4.0 makes promises to reduce materials waste, there is criticism that these new industry structures require more energy-intensive digital infrastructure and people skilled in creativity, and less of a labour force with "different skills" on site as in previous industrial systems and structures $[55,64]$. Coupled with the increase in vacant housing, the working structures that Industry 4.0 requires might attract a generation of young tech-savvy creative people who are not afraid to challenge the status quo of technology, but who are also part of the urban fabric and the disposable housing culture. To address this, since 2011, a renovation school has been held twice a year for students to learn do-it-yourself (DIY) construction and the business models to design a successful renovation project with limited start-up capital, resulting in new stores, cafes, share offices, guest houses, and other projects in Kitakyushu and beyond [28]. Media and local governments hail them, perhaps because these small enterprises are founded by the kind of citizens that a "Future City" like Kitakyushu needs [65], citizens who will fuel (and capitalise on) new technologies and ideas for businesses. Most of these small enterprises do not need big spaces and require only a small supply of a specialised skilled labour force. The housing obsolescence reflects a shift in sectoral economic structures (from Industry 2.0 to Industry 4.0) and spatial structures, and its unintended consequences, such as the displacement of long-term residents and abandonment of their houses, and an inflow of high-income people with different needs represented in their choice of housing.

In addition, many young people who do not challenge the status quo leave the city to obtain education and seek more thriving business opportunities, with the hope of climbing in social status. They often do not return to Kitakyushu. This idea of social mobility has been ingrained in the Japanese mentality since World War II, when the corporate sector became the heart of society, and does not accommodate a lot of flexibility regarding career changes or choice of location of housing. Japan, including Kitakyushu, is locked into a set of sociocultural and socioeconomic patterns, fostered by historical processes driven by the rise of more capitalist market-growth-oriented values, perhaps at the expense of the citizens and their connection with their land and their homes. However, Industry 4.0 might attract a new generation of young Japanese workers who can cope with the changes, like the massive rise in vacant housing, and help the elderly who are left behind. 


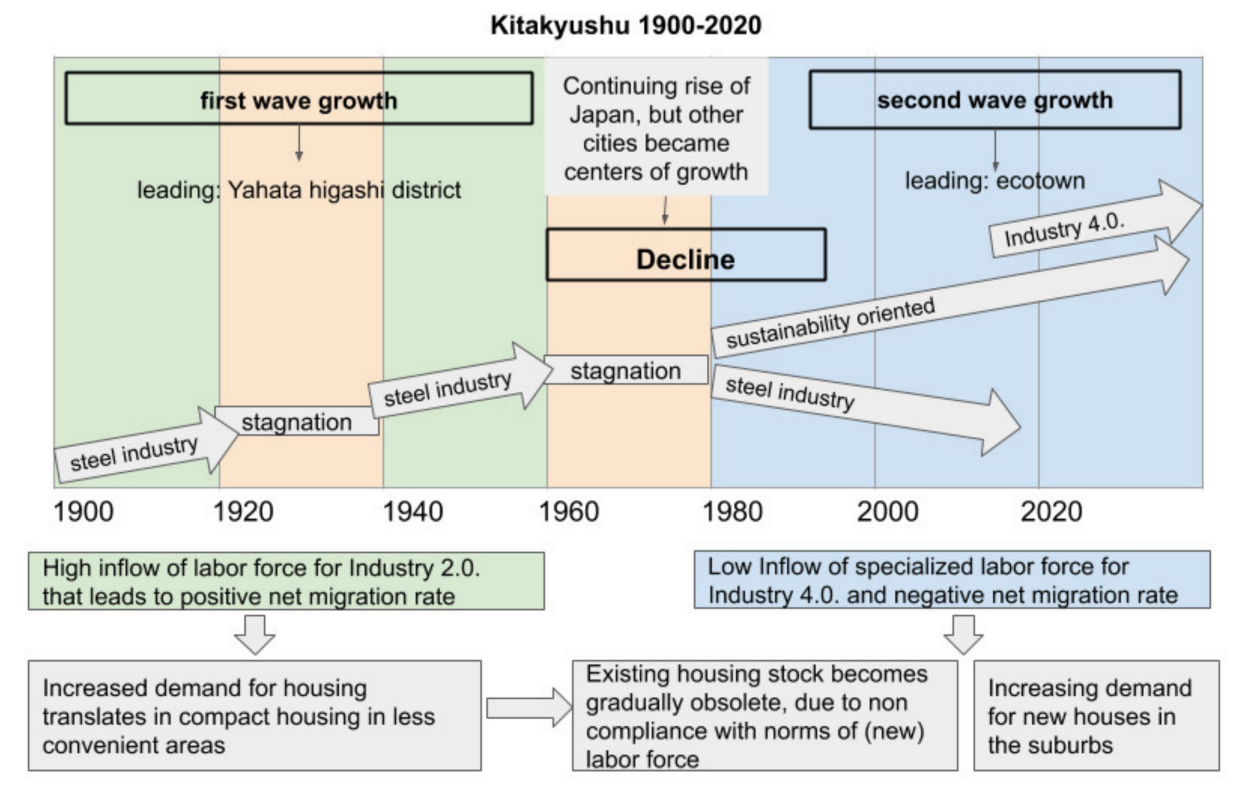

Figure 5. The relationship between unemployment (labour force) and the demand for housing for Kitakyushu over the last 120 years and the unintended effects on the built material stock.

Furthermore, in the research on circular economy, not much attention has been given to the human dimension or human resources (HR) essential for this transition [44]. There has also been a lack of focus on integrating a social justice perspective [62]; structural barriers (such as the working culture with its norms) hinder people from educating themselves and preparing to move from one labour pool to another. This would explain some unintended consequences of the displacement of long-term residents in places like Kitakyushu; they might, even more than usual, have the "right skills and HR" necessary for maintaining and restoring abandoned houses in the first place. In other words, for a circular approach, a city would need a stop the outflow of the labour force with the necessary skills for urban mining as well as attract an inflow of young workers who are open to such innovative transformations.

In addition, time is a central factor in the transition from linear to circular housing models. Even though time is a resource, it is also a condition for social reproduction, like using, maintaining, and renovating houses, or learning skills. In other words, people participating in such a transition need time to either teach or learn the requisite skills and knowledge. Decisions regarding home building are often seen as a masculine task [39]. This implies that in Japan, a country with distinct gender roles, men, in particular, need time to acquire these skills or search for the right labour, which calls for a gender dimension to material stock studies [66]. In the current capitalist model driving housing and other provisioning systems in modern, fast-paced society, time is perceived as a scarce commodity. This idea of time as a cost is reflected in the choice of action plans on abandoned housing of Kitakyushu's government based on convenience; it describes "arrangements, devices or services that helped save or shift time" [29]. Convenience is a herald of the fast-paced urban society. Although some people might see the newest norms and standards of convenience as criteria or indicators of wellbeing, they are not positive for everyone. A revisiting of the norms and standards of convenience and other domains is one of the prerequisites of the transition toward a circular built environment and the prevention of obsolete stock accumulation.

In addition, it is no surprise that Yahatahigashi has more dead than hibernating stock when compared with the two other districts, because this neighbourhood is locked in its industrial past and cannot accommodate the newest norms and codes (Figure 5). Based on these findings, the local government should especially design urban mining strategies, like opening a market for secondhand building materials, performing a deeper house-by-house assessment, and making a cost-benefit analysis, so that this district can encourage the local industry to not demolish these houses, but to instead deconstruct them and add value to the local economy by selling the building materials or 
components to growing markets in Japan and abroad—one recent study suggested sending Singapore's building components to Indonesia's growing market [17]. The local government can support the residents of Kokurakita with measures to stimulate renovating and "awakening" hibernating stocks, maybe with funds for preserving historical value. Yawatanishi's neighbourhood seems to be the result of interplay between the "favourable conditions" for the newest norms and the standards of the market. Its built environment seems to be altered more by market forces and national neoliberal housing policies [4] than by policy measures. If local governments do not have more power to interfere with these market forces and national housing policies, they might not have many options for this neighbourhood.

\section{Conclusions}

This article applied a heuristic model to the case of vacant housing in Kitakyushu and integrated tools and theories from political-industrial ecology with a spatial and temporal perspective to help policy-makers manage and understand vacant housing in support of a material stock-type society and a circular economy. This model classifies vacant houses into dead and hibernating stock. Dead stock is stock that likely cannot be sold for the service for which it was intended and cannot be kept due to (high) social costs, while hibernating stock still has the potential to serve society again via the purpose for which it was intended. We combined industrial ecology's quantitative tools from material stock and flow studies with a critical assessment of the socioeconomic environment in which these processes take place. Such a theory of political-industrial ecology allows for a holistic approach aiming at resource efficiency, integrating material, social, economic, and environmental dimensions.

The case of Kitakyushu demonstrates, in particular, the relationship between the historical trajectory of housing norms and standards, like comfort, cleanliness, safety, and convenience, and the dynamics among the built material stock, jobs, income, and demographic factors for the three selected districts: Kokurakita, Yahatanishi, and Yahatahigashi. The more locked-in a district's "obsolete norms and codes" are, the more likely it is that the obsolete stock is dead, as in the case of Yahatahigashi district. Consequently, urban mining should be considered the preferred strategy. This study contributes to the body of research on obsolescence and durability; historical studies reveal patterns and insights that can help policymakers to prevent the accumulation of more obsolete stock in their areas, and, in the case of developing countries, avoid the trajectory that the city of Kitakyushu and other similar cases took.

The next steps for researchers to expand this model are to calculate the material stock embodied in the houses we classified as dead stock, as they seem to be more suitable for urban mining. However, even if it is possible to estimate how much wood, reinforced concrete, and steel is available, it is not possible to know their quality. Second, not all in-use housing is employed full-time, such as second homes or houses that are temporarily vacant for manifold reasons such as being on sale or having unclear ownership. Hence, it is vital to integrate the idea of full- or part-time use into material stock studies.

Third, the quantitative assessment is static because we only used data on vacancy for one period. To move toward a dynamic model and test the sensitivity of input factors in the future, surveys have to be conducted over several years, which will make the model more complex, because the distribution of vacancy gets reshuffled over time (cf. urban life-cycle theories, e.g., [67]).

In addition, this research showed how the "urban measles" is a symptom of a complex array of interrelated variables and factors, like regulatory and environmental requirements, the dynamics of the urban housing market, and resident preferences that are rooted in the capitalist logic of property ownership and capital accumulation. Circular business models prioritise use over ownership, but for Japan, this shift would require a change in its strict ownership protections. Future research should include experts on law and urbanism to find solutions to facilitate the activation of existing housing stock in central but less attractive areas of the city. Second, this study sheds light on the impact of a shift from industrial structures on the housing metabolism of a city. In this regard, an important finding is that more insights are needed about the human dimension of the circular economy. Laws, research, 
and education have an influence on culturally accepted standards and citizen expectations regarding the quality of houses, which then dictate the quantity and quality of material flows and stocks within a city. Therefore, it can be concluded that there need to be more studies to better understand the impact of continually changing norms and standards regarding comfort, cleanliness, convenience, and security on consumption patterns of housing.

Author Contributions: Conceptualization, W.W. and R.S.; methodology, W.W. and H.T.; software, M.M.; validation, H.T.; formal analysis, W.W. and M.M.; data curation, H.T.; writing-original draft preparation, W.W.; writing-review and editing, R.S.; visualization, W.W. and R.S.; supervision, H.T.; funding acquisition, H.T. All authors have read and agreed to the published version of the manuscript.

Funding: This research was financially supported by the Ministry of Education, Culture, Sports, Science and Technology, Japan (MEXT); the Environment Research and Technology Development fund (S18-4-2, 3-1902, 1-2003) of the Ministry of the Environment, Japan, and Policy Study for Green Economy, Ministry of the Environment, Japan.

Acknowledgments: The authors want to thank Alessio Miatto, Mariana Ortega-Ramirez, and the three anonymous reviewers for comments on previous drafts, as well as Marie Hatada for her Japanese-English interpretations and the graduates from the Tanikawa laboratory team who contributed to the development of the 4D-GIS dataset of Kitakyushu over the past few years.

Conflicts of Interest: The authors declare no conflict of interest.

\section{References}

1. Harding, R. Is This the Solution to Japan's Glut of Empty Homes? Financial Times. 17 July 2015. Available online: https://www.ft.com/content/79297b7e-24c6-11e5-bd83-71cb60e8f08c (accessed on 20 December 2019).

2. Hattori, K.; Kaido, K.; Matsuyuki, M. The development of urban shrinkage discourse and policy response in Japan. Cities 2017, 69, 124-132. [CrossRef]

3. Japanese Ministry of Internal Affairs and Communications. Housing and Land Survey 2018. 2019. Available online: https:/www.e-stat.go.jp/en/stat-search/files?page $=1 \&$ toukei=00200522\&tstat=000001127155 (accessed on 20 December 2019).

4. Kubo, T.; Yui, Y. The Rise in Vacant Housing in Post-Growth Japan: Housing Market, Urban Policy, and Revitalizing Aging Cities; Springer: Singapore, 2019.

5. Nishiyama, H. A Problem of Vacant Housing in Local Cities: Utsunomiya City, Tochigi. In The Rise in Vacant Housing in Post-Growth Japan: Housing Market, Urban Policy, and Revitalizing Aging Cities; Springer: Singapore, 2019; p. 123.

6. Wuyts, W.; Miatto, A.; Sedlitzky, R.; Tanikawa, H. Extending or ending the life of residential buildings in Japan: A social circular economy approach to the problem of short-lived constructions. J. Clean. Prod. 2019, 231, 660-670. [CrossRef]

7. Pomponi, F.; Moncaster, A. Circular economy for the built environment: A research framework. J. Clean. Prod. 2017, 143, 710-718. [CrossRef]

8. Haase, A.; Rink, D.; Grossmann, K.; Bernt, M.; Mykhnenko, V. Conceptualizing urban shrinkage. Environ. Plan. A 2014, 46, 1519-1534. [CrossRef]

9. Döringer, S.; Uchiyama, Y.; Penker, M.; Kohsaka, R. A meta-analysis of shrinking cities in Europe and Japan. Towards an integrative research agenda. Eur. Plan. Stud. 2019, 1-20. [CrossRef]

10. Kubo, T.; Mashita, M. Why the Rise in Urban Housing Vacancies Occurred and Matters in Japan. In The Rise in Vacant Housing in Post-Growth Japan; Springer: Singapore, 2020; pp. 3-22.

11. Ghisellini, P.; Cialani, C.; Ulgiati, S. A review on circular economy: The expected transition to a balanced interplay of environmental and economic systems. J. Clean. Prod. 2016, 114, 11-32. [CrossRef]

12. Marin, J.; De Meulder, B. Interpreting circularity. Circular city representations concealing transition drivers. Sustainability 2018, 10, 1310. [CrossRef]

13. Miatto, A.; Schandl, H.; Forlin, L.; Ronzani, F.; Borin, P.; Giordano, A.; Tanikawa, H. A spatial analysis of material stock accumulation and demolition waste potential of buildings: A case study of Padua. Resour. Conserv. Recycl. 2019, 142, 245-256. [CrossRef]

14. Lanau, M.; Liu, G.; Kral, U.; Wiedenhofer, D.; Keijzer, E.; Yu, C.; Ehlert, C. Taking stock of built environment stock studies: Progress and prospects. Environ. Sci. Technol. 2019, 53, 8499-8515. [CrossRef] 
15. Okamoto, H. Switching to a Stock-Type Society-Creating Infrastructure in the Age of Long Lifespan Products; Kajima Publishing Co.: Tokyo, Japan, 2006. (In Japanese)

16. Humer, A.; Sedlitzky, R.; Brunner, D. When does population growth pay off? A case study of suburban land consumption to assess the Lower Austrian infrastructural cost calculator. J. Hous. Built Environ. 2019, 34, 331-344. [CrossRef] [PubMed]

17. Arora, M.; Raspall, F.; Cheah, L.; Silva, A. Buildings and the circular economy: Estimating urban mining, recovery and reuse potential of building components. Resour. Conserv. Recycl. 2020, 154, 104581. [CrossRef]

18. Brunner, P.H. In search of the final sink. Environ. Sci. Pollut. Res. 1999, 6, 1. [CrossRef] [PubMed]

19. Morris, E.W.; Winter, M. A theory of family housing adjustment. J. Marriage Fam. 1975, 37, 79-88. [CrossRef]

20. Thomsen, A.; Van der Flier, K. Understanding obsolescence: A conceptual model for buildings. Build. Res. Inf. 2011, 39, 352-362. [CrossRef]

21. Tanikawa, H.; Hashimoto, S. Urban stock over time: Spatial material stock analysis using 4d-GIS. Build. Res. Inf. 2009, 37, 483-502. [CrossRef]

22. Heisel, F.; Rau-Oberhuber, S. Calculation and evaluation of circularity indicators for the built environment using the case studies of UMAR and Madaster. J. Clean. Prod. 2020, 243, 118482. [CrossRef]

23. Irvine, S.; Bai, X. Positive inertia and proactive influencing towards sustainability: Systems analysis of a frontrunner city. Urban Transform. 2019, 1, 1. [CrossRef]

24. Japanese Ministry of the Environment. Eco Town's Progress and Development. 2018. Available online: http://www.env.go.jp/recycle/ecotown/index.html (accessed on 20 February 2020).

25. Shiroyama, H.; Kajiki, S. Case Study of Eco-town Project in Kitakyushu: Tension among Incumbents and the Transition from Industrial City to Green City. In Governance of Urban Sustainability Transitions; Springer: Tokyo, Japan, 2016.

26. Kazuhiko, S. Development of government buildings and company housing at Yahata Works and urban area formation. Urban Hous. Stud. 2010, 68, 37-42. (In Japanese)

27. Waswo, A. Housing in Postwar Japan-A Social History; Routledge: Abingdon, UK, 2013.

28. Holden, S. Renovation Culture in Kokura. Dispatches from Post-Growth Japan. 2015. Available online: https: //medium.com/dispatches-from-post-growth-japan/renovation-culture-in-kokura-a8a1e3925750 (accessed on 20 December 2019).

29. Shove, E. Converging conventions of comfort, cleanliness and convenience. J. Consum. Policy 2003, 26, 395-418. [CrossRef]

30. Pallagst, K.; Wiechmann, T.; Martinez-Fernandez, C. Shrinking Cities: International Perspectives and Policy Implications; Routledge: Abingdon, UK, 2013.

31. Radzimski, A. Changing policy responses to shrinkage: The case of dealing with housing vacancies in Eastern Germany. Cities 2016, 50, 197-205. [CrossRef]

32. Newell, J.P.; Cousins, J.J. The boundaries of urban metabolism: Towards a political-industrial ecology. Prog. Hum. Geogr. 2015, 39, 702-728. [CrossRef]

33. Danneels, K.; Juwet, G.; Bruggeman, D. Stedelijk metabolisme: Van theoretisch concept naar tastbare praktijk. AGORA Mag. 2018, 34, 4-7. (In Dutch) [CrossRef]

34. Breetz, H.L. Political-industrial ecology: Integrative, complementary, and critical approaches. Geofurom 2017, 85, 392-395. [CrossRef]

35. Cousins, J.J.; Newell, J.P. A political-industrial ecology of water supply infrastructure for Los Angeles. Geoforum 2015, 58, 38-50. [CrossRef]

36. Chertow, M.R. Industrial symbiosis: Literature and taxonomy. Ann. Rev. Energy Environ. 2000, 25, 313-337. [CrossRef]

37. Fischer-Kowalski, M.; Haberl, H. Sustainable development. Longterm changes in socio-economic metabolism and colonization of nature. Int. Soc. Sci. J. 1998, 158, 573-587. [CrossRef]

38. Tanikawa, H.; Fishman, T.; Okuoka, K.; Sugimoto, K. The weight of society over time and space: A comprehensive account of the construction material stock of Japan, 1945-2010. J. Ind. Ecol. 2015, 19, 778-791. [CrossRef]

39. Cox, R. Materials, skills and gender identities: Men, women and home improvement practices in New Zealand. Gend. Place Cult. 2016, 23, 572-588. [CrossRef]

40. Leonard, L.; Perkins, H.; Thorns, D. Presenting and creating home: The influence of popular and building trade print media in the construction of home. Hous. Theory Soc. 2004, 21, 97-110. [CrossRef] 
41. Avrami, E. Making historic preservation sustainable. J. Am. Plan. Assoc. 2016, 82, 104-112. [CrossRef]

42. Cheng, K.L.; Hsu, S.C.; Li, W.M.; Ma, H.W. Quantifying potential anthropogenic resources of buildings through hot spot analysis. Resour. Conserv. Recycl. 2018, 133, 10-20. [CrossRef]

43. Miatto, A.; Schandl, H.; Tanikawa, H. How important are realistic building lifespan assumptions for material stock and demolition waste accounts? Resour. Conserv. Recycl. 2017, 122, 143-154. [CrossRef]

44. Jabbour, C.J.C.; Sarkis, J.; de Sousa Jabbour, A.B.L.; Renwick, D.W.S.; Singh, S.K.; Grebinevych, O.; Kruglianskas, I.; Godinho Filho, M. Who is in charge? A review and a research agenda on the 'human side'of the circular economy. J. Clean. Prod. 2019, 222, 793-801. [CrossRef]

45. Sing, M.C.; Love, P.E.; Liu, H.J. Rehabilitation of existing building stock: A system dynamics model to support policy development. Cities 2019, 87, 142-152. [CrossRef]

46. Wuyts, W. Market distortions encouraging wasteful consumption. In Responsible Consumption and Production; Encyclopedia of the UN Sustainable Development Goals; Leal Filho, W., Azul, A., Brandli, L., Özuyar, P., Wall, T., Eds.; Springer: Cham, Switzerland, 2019. [CrossRef]

47. Camacho-Otero, J.; Boks, C.; Pettersen, I.N. Consumption in the circular economy: A literature review. Sustainability 2018, 10, 2758. [CrossRef]

48. Camacho-Otero, J.; Pettersen, I.N.; Boks, C. Consumer engagement in the circular economy: Exploring clothes swapping in emerging economies from a social practice perspective. Sustain. Dev. 2019, 28, 279-293. [CrossRef]

49. Kitakyushu City. Kitakyushu Vacant Housing (Action Plan). 2016. Available online: https://www.city. kitakyushu.lg.jp/files/000740825.pdf (accessed on 10 February 2020).

50. Kitakyushu City. Kitakyushu Vacant Housing (Executive Summary). 2016. Available online: https: //www.city.kitakyushu.lg.jp/files/000740825.pdf (accessed on 10 February 2020).

51. Kitakyushu City. Location Optimization Plan. 2019. Available online: https://www.city.kitakyushu.lg.jp/kento/07900223.html (accessed on 10 February 2020).

52. Kitakyushu City. Local Statistics of Population Census of KITAKYUSHU Government. 2019. Available online: https://www.city.kitakyushu.lg.jp/soumu/file_0311.html (accessed on 10 February 2020).

53. Kitakyushu City University. Kitakyushu City Planning GIS Data, DVD version; Kitakyushu City University: Kitakyushu, Japan, 2016.

54. Curran, W.; Hamilton, T. Just green enough: Contesting environmental gentrification in Greenpoint, Brooklyn. Local Environ. 2012, 17, 1027-1042. [CrossRef]

55. Curran, W.; Hamilton, T. Just Green Enough: Urban Development and Environmental Gentrification; Routledge: Abingdon, UK, 2017.

56. Nishiyama, H. Resolution of Vacant Housing Through Social Business: Kominka Renovation Business by Nakagawa Jyuken Corp. In The Rise in Vacant Housing in Post-Growth Japan; Springer: Singapore, 2020; pp. 149-160.

57. Ishikawa, M.; Matsuhashi, K.; Ariga, T.; Kanamori, Y.; Kurishima, H. Estimation of current and future distribution of vacant dwellings within municipalities: With a focus on the difference between the numbers of dwellings and households. J. City Plan. Inst. Jpn. 2016, 51, 833-838. (In Japanese)

58. Ishikawa, M.; Matsuhashi, K.; Kanamori, Y.; Ariga, T. Method of grasping detailed regional distribution of vacant dwelling based on the number of dwellings and households. Trans. CPIJ 2017, 52, 689-695. (In Japanese)

59. Yamashita, S.; Morimoto, A. Study on occurrence pattern of the vacant houses in the local hub city. J. City Plan. Inst. Jpn. 2015, 50, 932-937.

60. Augiseau, V.; Barles, S. Studying construction materials flows and stock: A review. Resour. Conserv. Recycl. 2017, 123, 153-164. [CrossRef]

61. Sandberg, N.H.; Sartori, I.; Brattebø, H. Sensitivity analysis in long-term dynamic building stock modeling-Exploring the importance of uncertainty of input parameters in Norwegian segmented dwelling stock model. Energy Build. 2014, 85, 136-144. [CrossRef]

62. Kirchherr, J.; Reike, D.; Hekkert, M. Conceptualizing the circular economy: An analysis of 114 definitions. Resour. Conserv. Recycl. 2017, 127, 221-232. [CrossRef]

63. Grinin, L.E.; Grinin, A.L.; Korotayev, A. Forthcoming Kondratieff wave, Cybernetic Revolution, and global ageing. Technol. Forecast. Soc. Change 2017, 115, 52-68. [CrossRef]

64. Florida, R. Cities and the Creative Class; Routledge: Abingdon, UK, 2005. 
65. Japanese Government. Growth Strategy 2018. Basic Outlook and Key Strategies. 2018. Available online: http://www.kantei.go.jp/jp/singi/keizaisaisei/pdf/miraitousi2018_en.pdf (accessed on 11 December 2019).

66. Wuyts, W. Over huisvrouwen en leegstaande woningen in Japan. AGORA Mag. 2018, 34, 32-35. (In Dutch) [CrossRef]

67. Berg, L.V.D.; Drewett, R.; Klaasen, L.H.; Rossi, A.; Vijverberg, C.H. Urban Europe: A Study of Growth and Decline; Costs Urban Growth (curb) Project 1; Pergamon Press: Oxford, UK, 1982; Volume 1, pp. $24-48$.

(C) 2020 by the authors. Licensee MDPI, Basel, Switzerland. This article is an open access article distributed under the terms and conditions of the Creative Commons Attribution (CC BY) license (http://creativecommons.org/licenses/by/4.0/). 